\title{
Pembangkitan Pulsa Orde Nanodetik Berbasis Mikrokontroler Untuk Eksitasi Transduser Ultrasonik
}

\author{
FAATIH RIFQI MUQAFFI, BAMBANG MUKTI WIBAWA, DARMAWAN \\ HIDAYAT
}

\author{
Department of Electrical Engineering, Universitas Padjadjaran, Indonesia \\ Email: darmawan.hidayat@unpad.ac.id
}

Received 10 Desember 201x | Revised 5 Januari 2020 | Accepted 20 Januari 2020

\begin{abstract}
ABSTRAK
Makalah ini melaporkan suatu teknik pembangkitan pulsa lebar orde nanodetik (ns) repetitif yang terprogram berbasis mikrokontroler untuk keperluan eksitasi transduser ultrasonik. Pembangkitan pulsa dan pengaturan jarak antar pulsa dilakukan melalui operasi timer mikrokontroler. Sebuah monostable multivibrator mengubah lebar pulsa dari mikrokontroler dalam orde nanodetik melalui pengaturan komponen pewaktuan resistor-kapasitor $(R C)$ dengan cara pengaturan nilai $R$ yang dibuat dari sebuah potensiometer digital. Hasil pengujian menunjukkan bahwa mikrokontroler membangkitkan pulsa repetitif dengan interval terprogram dalam orde 1 detik dan lebar pulsa minimum 1,25 ms. monostable multivibrator dapat mengubah lebar pulsa tersebut menjadi sekitar 140 ns. Berdasarkan hasil pengujian, dapat disimpulkan bahwa sistem berfungsi sesuai rancangan, sistem dapat membangkitkan pulsa repetitif dengan lebar pulsa hingga 140 ns dengan parameter interval dan lebar yang dapat diprogram.
\end{abstract}

Kata kunci: generator pulsa, lebar pulsa singkat, mikrokontroler, monostable multivibrator, eksitasi transduser ultrasonik

\begin{abstract}
This paper reports a repetitive, programmable, microcontroller-based pulse width generation technique for the purpose of ultrasonic transducer excitation. Pulse generation and distance adjustment between pulses is done through the microcontroller timer. A monostable multivibrator changes the pulse width of the microcontroller in the order of nanoseconds by adjusting the resistor-capacitor time constant which are done by adjusting the $R$ value made from a digital potentiometer. The test results show that the microcontroller generates repetitive pulses with programmed intervals in order of 1 second and pulse width of $1.25 \mathrm{~ms}$. A monostable multivibrator converts the pulse width to ca. $140 \mathrm{~ns}$. Based on the test results, it can be concluded that the system functions according to the design as the system can generate repetitive pulses with pulse widths up to 140 nanoseconds with programmable interval and width parameters.
\end{abstract}

Keywords: pulse generator, short-width pulse, microcontroller, monostable multivibrator, ultrasonic transducer excitation 
Muqaffi, dkk

\section{PENDAHULUAN}

Gelombang ultrasonik banyak digunakan untuk aplikasi-aplikasi pengujian tak-merusak (NDT) terhadap objek atau medium uji karena relatif murah, sederhana, dan cepat (Ingale \& Kale, 2017; Jaffar, K, \& Y.B, 2016). Pembangkitan gelombang ultrasonik berbasis elemen aktif piezoelektrik dapat dilakukan dengan memicu transduser oleh sinyal listrik dalam bentuk pulsa (Chaney \& Sundararajan, 2004; Darmawan Hidayat, Setianto, Syafei, \& Wibawa, 2018). Teknik ini memiliki fleksibilitas dalam implementasi dan akusisi sinyal (Svilainis, Chaziachmetovas, \& Dumbrava, 2015). Transduser ultrasonik mengubah pulsa listrik menjadi energi dalam bentuk gelombang akustik. Transduser bervibrasi dan membangkitkan gelombang ultrasonik jika dieksitasi pulsa tegangan-tinggi. Gelombang ultrasonik tersebut selanjutnya dirambatkan ke objek atau medium uji dan diterima kembali oleh transduser penerima. Gelombang terima selanjutnya diproses untuk memeroleh berbagai informasi tentang objek atau medium uji tersebut. Pulsa eksitasi ini dapat dibangkitkan dengan penyaklaran (switching) tegangan tinggi searah (DC) oleh pulsa penggerak (drive) yang dibangkitkan dari suatu generator pulsa (Darmawan Hidayat, Ismail, Syafei, \& Wibawa, 2018; Darmawan Hidayat, Syafei, Wibawa, \& Tumbelaka, 2018). Frekuensi kerja transduser menentukan lebar pulsa eksitasi yang tepat agar transduser membangkitkan gelombang ultrasonik pada frekuensi kerjanya (D. Hidayat, Syafei, Wibawa, \& Tumbelaka, 2018). Pada pembangkitan gelombang ultrasonik frekuensi tinggi (di atas 1 $\mathrm{MHz}$ ) dan daya tinggi berbasis piezoelektrik, eksitasi transduser membutuhkan pulsa singkat (dalam orde kurang dari 500 nanodetik atau sub-nanodetik) dan tegangan tinggi (dalam orde ratusan volt) karena pulsa singkat ini mengandung sinyal spektrum yang lebar dan frekuensi tinggi (D. Hidayat, Syafei, et al., 2018). Jadi, sistem generator pulsa penggerak memegang peranan kunci dalam perangkat/teknologi berbasis gelombang ultrasonik (Ega, Suhendi Syafei, Mukti Wibawa, \& Hidayat, 2016).

Terdapat beberapa generator pulsa komersial untuk keperluan eksitasi transduser ultrasonik, seperti tipe PR5900 (Panametrics Inc, Waltham, MA, USA). Namun perangkat komersial memiliki beberapa keterbatasan dalam sensitivitas ketika digunakan untuk proses pencitraan berbasis-ultrasonik frekuensi tinggi (Wu, Chen, Wang, Chen, \& Chen, n.d.). Selain itu, faktor akses harga menjadi kendala ekonomis ketika suatu aplikasi memerlukan lebih dari satu perangkat. Oleh karena itu, diperlukan suatu alternatif generator pulsa eksitasi yang dapat digunakan untuk eksitasi transduser frekuensi tinggi (di atas $1 \mathrm{MHz}$ ) dengan fitur yang dapat diprogram sesuai kebutuhan pengguna dan perangkat ini dapat diperoleh dan diproduksi dengan harga terjangkau. Beberapa sistem generator pulsa dibangun berbasis mikrokontroler. Penggunaan mikrokontroler memberikan peningkatan fitur dan kemudahan dalam operasional oleh pengguna (Aydn \& Güler, 2010; Vyaghra, Sharma, \& Rajagopalan, 2016). Makalah ini melaporkan rancangan dan pengujian sistem generator pulsa repetitif yang dibangun dari mikrokontroler Arduino dan monostable multivibrator sehingga lebar dan interval pulsa dapat diprogram masing-masing dalam orde $140 \mathrm{~ns}$ dan $1 \mu \mathrm{s}-1 \mathrm{~s}$.

\section{METODE}

\subsection{Blok Diagram Sistem}

Gambar 1 memperlihatkan blok diagram sistem dan proses pembentukan pulsa secara keseluruhan. Sistem keseluruhan dibangun dari dua blok utama yaitu bagian pertama adalah pembangkit pulsa dan blok kedua adalah pembentuk lebar pulsa (kotak garis putus-putus Gambar 1.a). Pembangkit pulsa dibangun dari komponen mikrokontroler Arduino Uno (ATmega328P) sebagai pengontrol, lima saklar tekan (push-button, PB) sebagai antarmuka pengaturan parameter-parameter pulsa dan sebuah peraga LCD $2 \times 16$ karakter sebagai 
penampil nilai-nilai parameter pulsa. Pembentuk lebar pulsa dibangun dari sebuah monostable multivibrator (dengan input picu Schmitt triggertepi positif) dan sebuah potensiometer digital. Monostable multivibrator dalam mode one-shot dibangun dari komponen IC TTL SN74121. Potensiometer digital adalah IC X9C103 (dari Intersil) memiliki nilai resistansi $0-10 \mathrm{k} \Omega$ yang terbagi dalam 100 tap (langkah) nilai resistansi, dan antarmuka serial. Skematik rangkaian keseluruhan ditampilkan seperti Gambar 3.

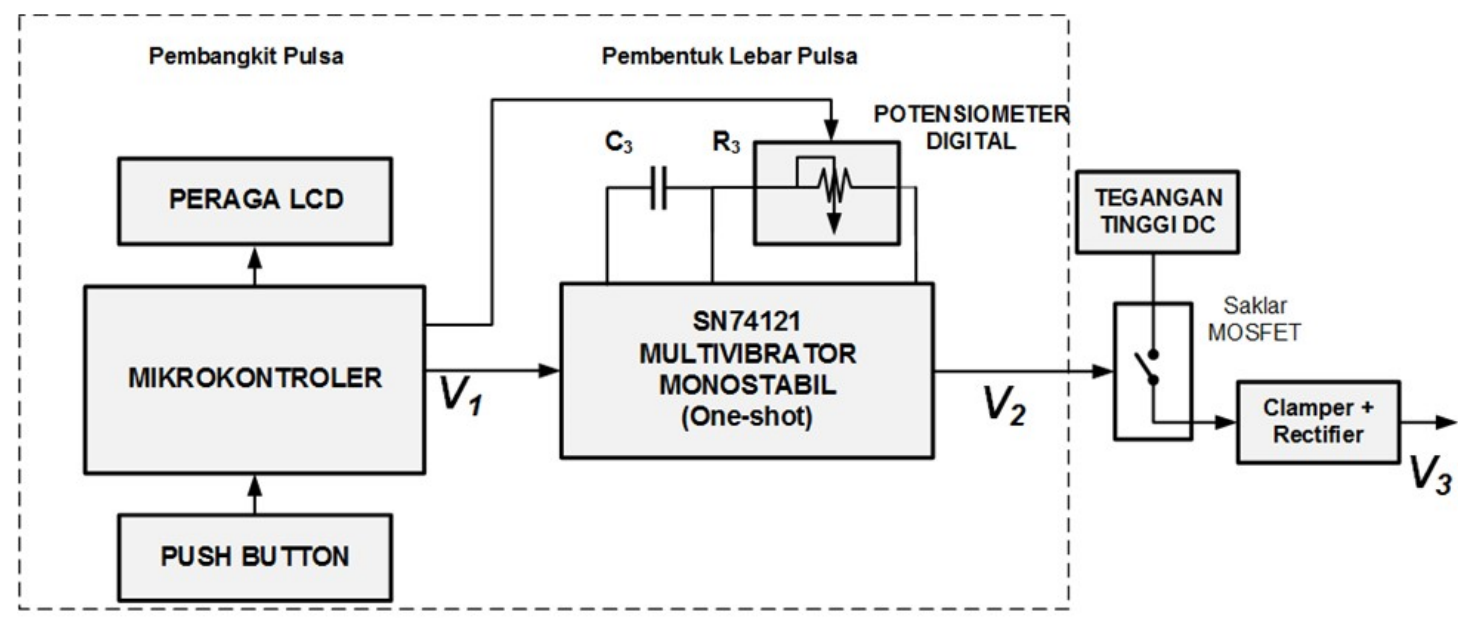

(a)

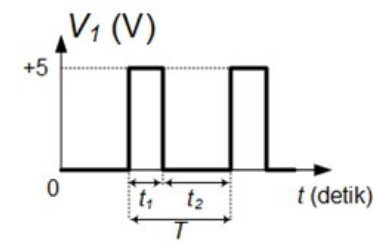

(b)

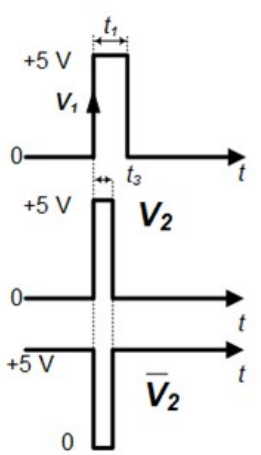

(c)

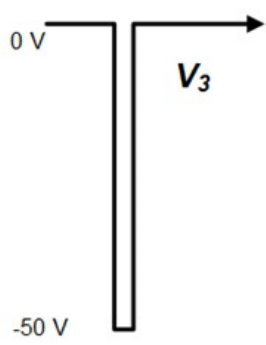

(d)

\section{Gambar 1. Blok Diagram Sistem Pembangkit Pulsa Terprogram Berbasis Mikrokontroler Dengan Lebar Pulsa Orde Nanodetik (a) Blok Diagram, (b) Bentuk Pulsa dari Mikrokontroler, (c) Pembentukan Lebar Pulsa Nanodetik dan (d) Pulsa Nanodetik yang Telah Dikuatkan Daya untuk Eksitasi Transduser}

Pulsa terprogram $V_{2}$ yang dibangkitkan dari sistem mikrokontroler dan monostable multivibrator masih memiliki daya rendah (level TTL) sehingga tidak cukup daya untuk eksitasi transduser ultrasonik. Untuk meningkatkan daya, pulsa $V_{2}$ selanjutnya dikuatkan melalui rangkaian penyaklaran tegangan tinggi MOSFET dan dibentuk oleh rangkaian penjepit (clamper) dan penyearah (rectifier) menjadi pulsa negatif -50 V sehingga menghasilkan pulsa $V_{3}$ seperti Gambar 1.d. Pulsa $V_{3}$ ini selanjutnya digunakan untuk eksitasi transduser.

Pengujian pulsa $V_{3}$ untuk eksitasi transduser dilakukan dengan cara mode transmisi perambatan gelombang ultrasonik dalam medium air menggunakan sepasang transduser identik jenis tercelup (immersible) yang memiliki frekuensi kerja masing-masing 1,00 $\pm 0,05$ $\mathrm{MHz}$ seperti pada Gambar 2. Pulsa $V_{3}$ mengeksitasi transduser pengirim Tx sehingga gelombang ultrasonik terbangkit dari Tx dan merambat melalui medium air. Gelombang 
ultrasonik yang telah merambat kemudian diterima oleh transduser, dikuatkan oleh amplifier, dan diterima oleh osiloskop (GW-Instek GDS2014) untuk ditampilkan dan direkam.

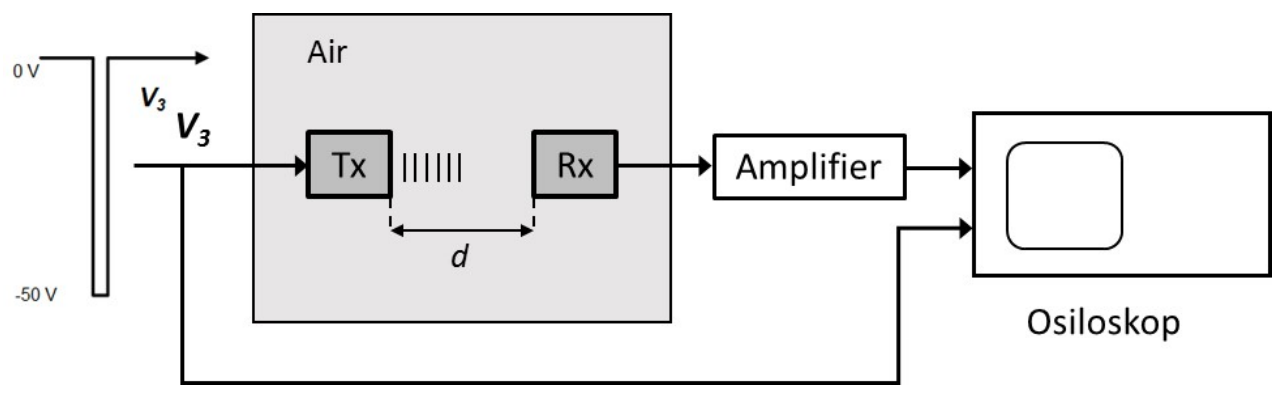

Gambar 2. Sistem Pengujian Pulsa $V_{3}$ untuk Eksitasi Transduser

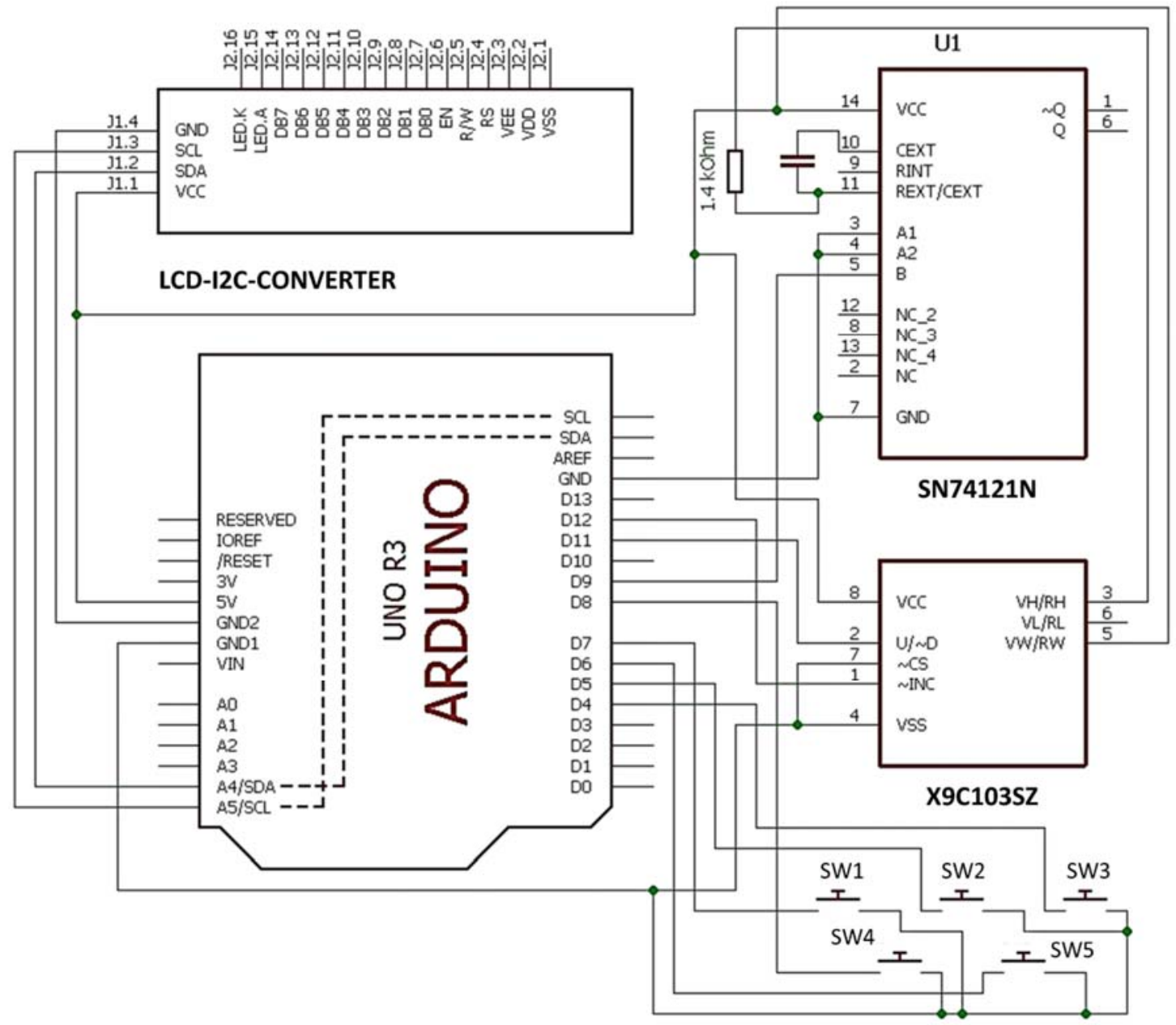

Gambar 3. Rangkaian Skematik Sistem Pembangkit Pulsa Terprogram Berbasis Mikrokontroler

\subsection{Perangkat Lunak}

Pembangkitan pulsa dilakukan oleh mikrokontroler dengan memanfaatkan pustaka (library) pembangkitan pulsa pulse-width modulation (PWM) melalui operasi Timer1 (bentuk pulsa ditampilkan seperti pada Gambar 1.b). Parameter pulsa meliputi lebar pulsa $\left(t_{1}\right)$ dan interval 
Pembangkitan Pulsa Orde Nanodetik Berbasis Mikrokontroler Untuk Eksitasi Transduser Ultrasonik

pulsa ( $T$ ) diatur melalui saklar PB. Peraga LCD menampilkan nilai-nilai parameter tersebut. Berikut adalah algoritma pembangkitan pulsa dengan contoh pengaturan nilai parameter $t_{1}$ adalah 512 ns dan $T$ sebesar 10.000 ns (10 ms).

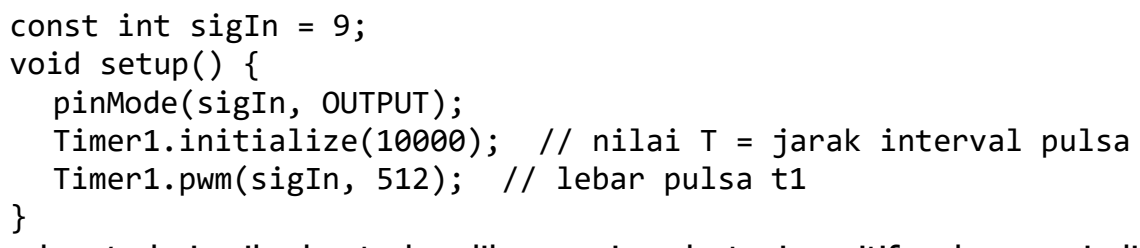

Lebar pulsa $t_{1}$ dari mikrokontroler dikonversi pada tepi positif pulsa menjadi $t_{3}$ dalam orde nanodetik oleh monostable multivibrator Schmitt trigger. Lebar pulsa keluaran multivibrator ini ditentukan oleh nilai pewaktuan dari rangkaian $R_{3}$ (yang dibangun dari potensiometer digital) dan $C_{3}$ yang dipasang sebesar 50 pF, mengikuti Persamaan (1) (Darmawan Hidayat, Setianto, et al., 2018).

$$
t_{3}=0,33 \times R_{3} \times C_{3}
$$

Nilai $R_{3}$ diatur oleh mikrokontroler melalui tiga saluran kontrol IC X9C103 yaitu pin U/D,$\overline{\mathrm{CS}}$ dan $\overline{\mathrm{INC}}$. Berikut adalah algoritma pengaturan nilai $R_{3}$ ke nilai minimum (nol $\Omega$ ) dengan melakukan cacah turun sebanyak 101 kali. Langkah ini dilakukan untuk memastikan nilai resistansi berangkat dari nol.

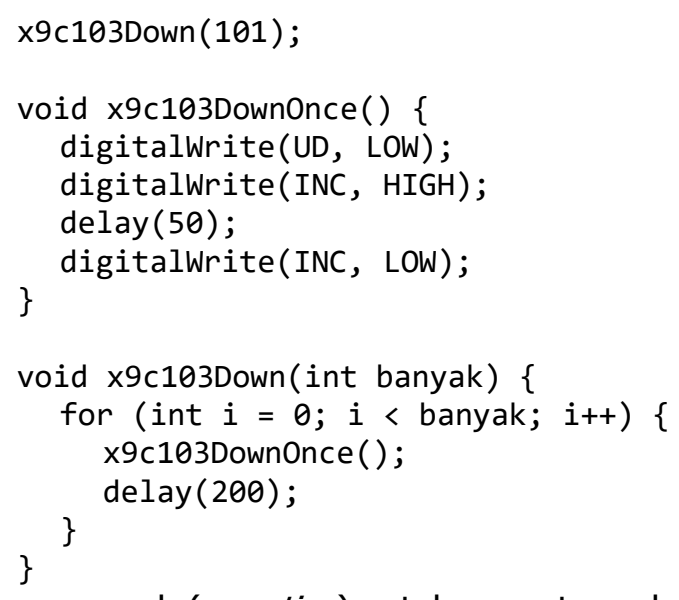

Kemudian proses cacah (counting) untuk pengaturan ke nilai $R_{3}$ tertentu dilakukan secara naik dari kondisi minimum dengan melakukan perulangan fungsi program sebagai berikut. Dengan rentang nilai resistansi IC X9C103 adalah $0-10 \mathrm{k} \Omega$ dan terdapat 100 langkah nilai, maka nilai resolusi potensiometer digital ini adalah $100 \Omega$ /langkah.

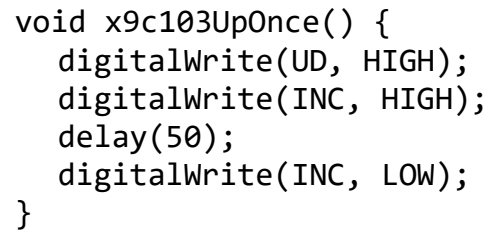

\subsection{Pengujian}

Pulsa yang dibangkitkan dari mikrokontroler dan pulsa konversi dari monostable multivibrator ditampilkan dan direkam dengan menggunakan osiloskop (GW-Instek 2104A). Interval pulsa diukur melalui pengukuran jarak pulsa berdampingan. Pengujian resistansi terhadap nilai 
cacahan IC X9C103 dilakukan seperti Gambar 4. Mikrokontroler memberikan nilai cacahan naik dengan cara membuat tinggi pin U/D dan memberikan tepi negatif pada pin $\overline{\text { INC }}$ sebanyak $n$ tap sesuai resolusi X9C103 sebesar $100 \Omega$ /tap. Nilai resistansi pada pin RH dan RW diukur menggunakan multimeter digital (Sanwa 800a).

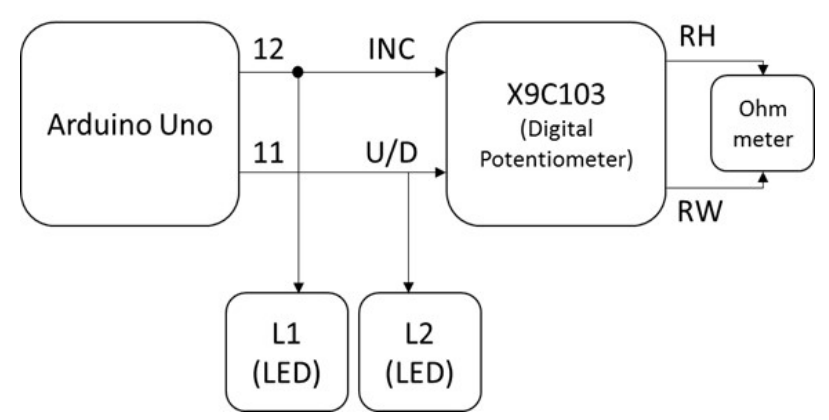

\section{Gambar 4. Blok Pengujian Resistansi terhadap Nilai Cacah IC X9C103}

\section{HASIL DAN PEMBAHASAN}

Gambar 5 memperlihatkan bentuk pulsa yang dibangkitkan di pin-9 dari mikrokontroler $V_{1}$ dengan variasi nilai desimal pada fungsi Timer1.initialize(nilai_desimal); adalah 1, 1000, 100000 dan 999.000 yang berhubungan dengan interval waktu $T$ sebesar $1 \mu \mathrm{s}, 1 \mathrm{~ms}$, $100 \mathrm{~ms}$ dan $1 \mathrm{~s}$. Dari hasil pengukuran pada tampilan osiloskop tampak bahwa bentuk sinyal yang dihasilkan adalah pulsa PWM. Siklus kerja pulsa $V_{1}$ adalah $50 \%$, artinya lebar $t_{1}$ sama dengan lebar $t_{2}$. Ketika nilai desimal fungsi diubah tampak bahwa lebar $T$ berubah memiliki interval pulsa $T$ adalah $1 \mu \mathrm{s}, 1 \mathrm{~ms}, 100 \mathrm{~ms}$ dan $1 \mathrm{~s}$, mengikuti sesuai dengan nilai desimal. Hasil pengukuran ini menunjukkan bahwa pulsa repetitif dengan nilai interval pulsa $T$ dapat dibangkitkan dari mikrokontroler melalui pengaturan nilai desimal pada fungsi.

Untuk tahap berikutnya, lebar $t_{1}$ diubah menjadi lebih pendek tanpa mengubah jarak interval $T$. Pengubahan $t_{1}$ menjadi $t_{3}$ dilakukan oleh multivibrator melalui pengaturan nilai resitansi potensiometer digital $R_{3}$. Untuk keperluan tersebut diperlukan potensiometer yang memiliki linearitas tinggi. Gambar 6 memperlihatkan nilai resistansi potensiometer digital IC X9C103 terhadap nilai cacahan $0-100$. Nilai korelasi antara resistansi dan nilai cacahan adalah $R^{2}=$ 0,9999 menandakan bahwa linearitas potensiometer digital sangat baik. Secara visual dapat dilihat garis yang lurus dengan linearitas tinggi menghubungkan resistansi dan nilai cacahan. 
Pembangkitan Pulsa Orde Nanodetik Berbasis Mikrokontroler Untuk Eksitasi Transduser Ultrasonik
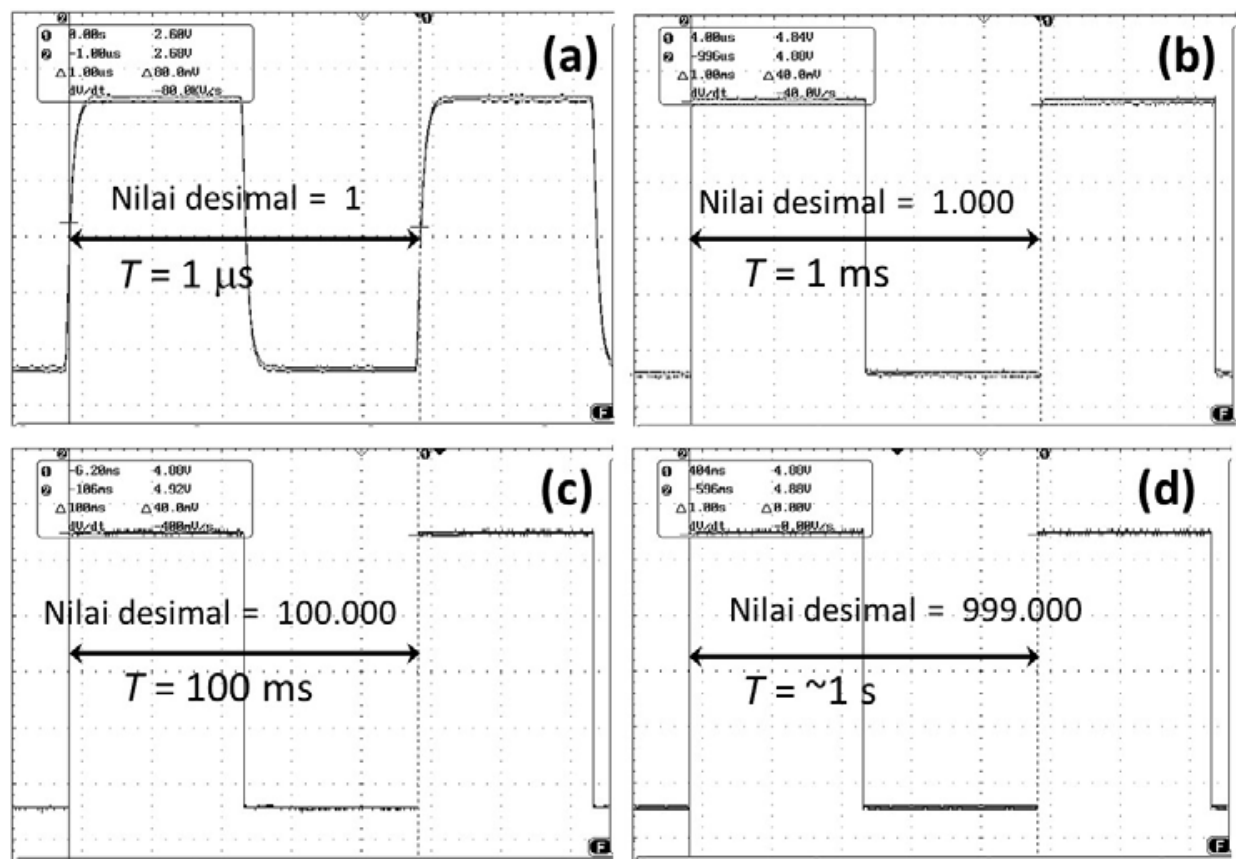

Gambar 5. Bentuk Pulsa dari Mikrokontroler Dengan Pengaturan Variasi Interval Pulsa $T$ Bernilai (a) $1 \mu \mathrm{s}$, (b) 1 ms, (c) 100 ms Dan (d) $1 \mathrm{~s}$

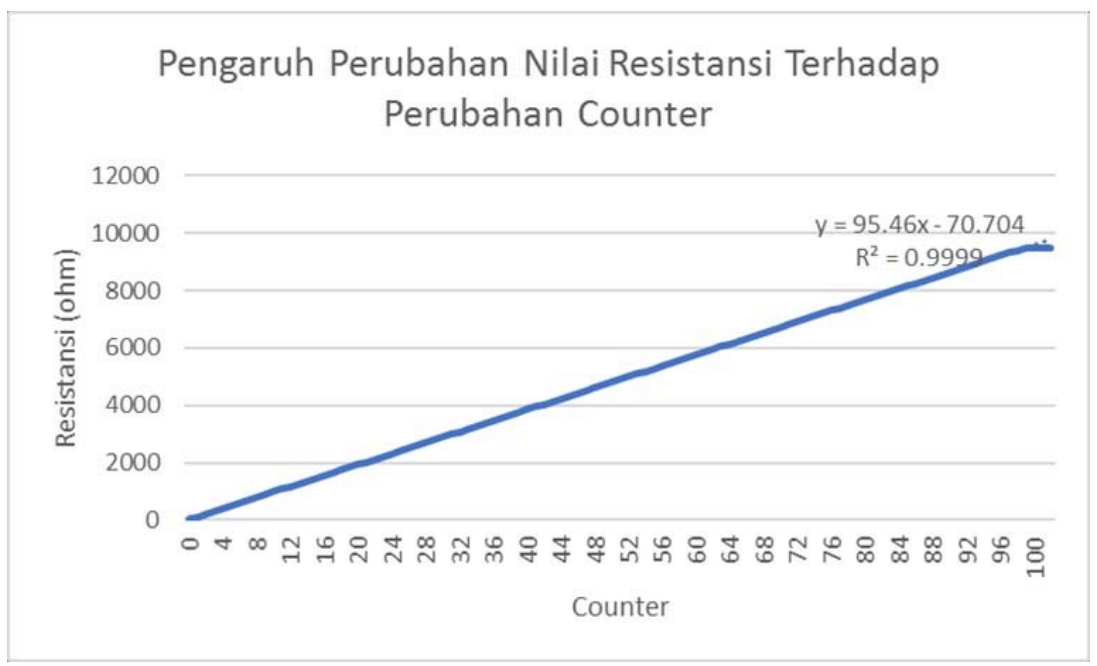

Gambar 6. Resistansi Potensiometer Digital terhadap Nilai Cacah 0 - 100 Desimal

Gambar 6 memperlihatkan proses konversi pulsa $V_{1}$ (lebar $t_{1}$ ) menjadi pulsa $V_{2}$ (lebar $t_{3}$ ) oleh monostable multivibrator SN74121. Lebar interval pulsa $V_{1}$ adalah $1 \mathrm{~s}$ atau lebar $t_{1} 500 \mathrm{~ms}$ (dengan siklus kerja 50\%). Dengan nilai $R_{3}$ dan $C_{3}$ masing-masing adalah $4400 \Omega$ dan $50 \mathrm{pF}$, maka secara perhitungan dari Persamaan 1 nilai $t_{3}$ adalah 151,8 ns. Hasil pengukuran pada Gambar 7 menunjukkan bahwa lebar pulsa $t_{3}$ adalah 140 ns (terdapat selisih dengan hasil perhitungan 151,8 ns) dengan lebar pulsa sama dengan $V_{1}$ yaitu $1 \mathrm{~s}$. Hasil ini menunjukkan bahwa lebar pulsa $V_{1}$ sebesar $t_{1} 500$ ms telah diubah menjadi pulsa singkat orde $140 \mathrm{~ns}$ tanpa mengubah lebar interval pulsa. 


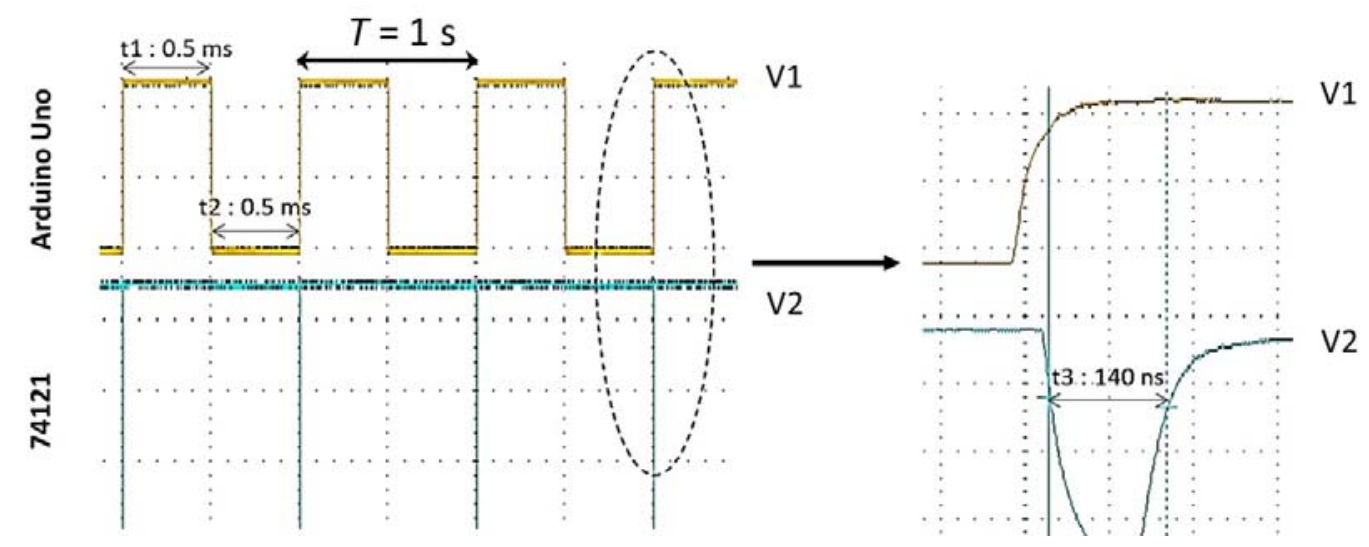

Gambar 7. Bentuk Pulsa yang Dibangkitkan oleh Mikrokontroler $\left(V_{1}\right)$ dengan Lebar Pulsa $T_{1}$ adalah 0,5 S dan Pulsa Hasil Konversi oleh Monostable Multivibrator $\left(V_{2}\right)$ dengan Nilai $R_{3}=4400 \Omega$ dan $C_{3}=50 \mathrm{pF}$

Untuk memastikan fungsi kerja monostable multivibrator dalam pembentukan pulsa singkat, maka selanjutnya ditinjau lebar pulsa $t_{1}$ lebih lebar dari pulsa $V_{1}$ pada Gambar 7 , yaitu sebesar 8,75 ms (atau siklus kerja 87,5\%) dengan jarak interval $T$ sebesar $10 \mathrm{~ms}$.

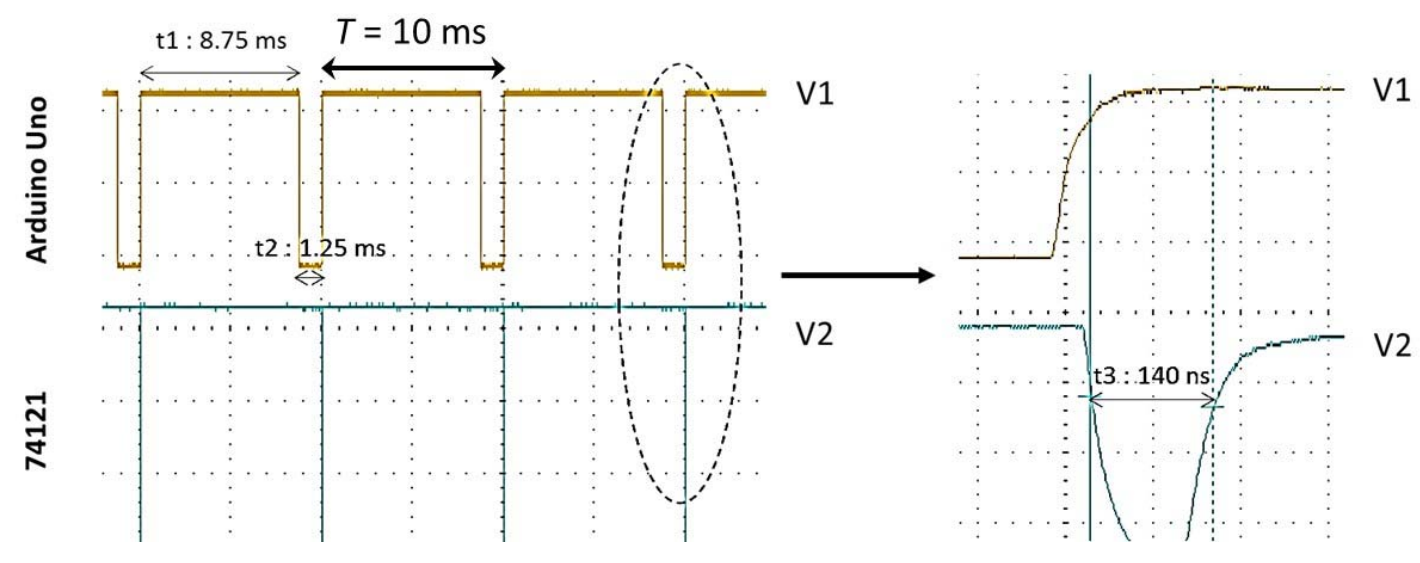

Gambar 8. Bentuk Pulsa yang Dibangkitkan oleh Mikrokontroler $\left(V_{1}\right)$ dengan Lebar Pulsa $T_{1}$ Adalah 8,75 ms dan Pulsa Hasil Konversi oleh Monostable Multivibrator ( $\left.V_{2}\right)$ dengan Nilai $R_{3}=4400 \Omega$ dan $C_{3}=50 \mathrm{pF}$

Gambar 8 memperlihatkan ketika lebar pulsa $t_{1}$ dinaikkan menjadi $8,75 \mathrm{~ms}$, lebar pulsa $t_{3}$ tetap tidak berubah sebesar 140 ns mengikuti nilai pengaturan $R_{3}$ dan $C_{3}$ sebelumnya. Nilai interval pulsa pada pulsa $t_{3}$ juga tidak berubah, sama dengan interval pulsa pada pulsa $t_{1}$ sebesar 10 ms. Selain itu, pengujian juga dilakukan untuk berbagai nilai lebar pulsa $t_{1}$ dalam rentang $0,125 \mathrm{~ms}$ hingga 437,5 ms. Gambar 9 memperlihatkan plot hubungan antara lebar pulsa $t_{3}$ dengan lebar pulsa $t 1$. Tampak bahwa dengan variasi nilai lebar pulsa $t_{1}$ dengan nilai $0,125-$ $437,5 \mathrm{~ms}$, lebar pulsa $t_{3}$ tetap sebesar 140 ns sesuai dengan kombinasi nilai $R_{3}$ dan $C_{3}$. Hasil pengujian yang disajikan Gambar 6,7 dan 8 menunjukkan bahwa lebar pulsa $t_{3}$ hanya ditentukan oleh nilai $R_{3}$ dan $C_{3}$, tidak bergantung pada lebar pulsa $t_{1}$. Nilai interval pulsa $T$ pada $V_{2}$ juga sama dengan lebar interval $V_{1}$, dan tidak bergantung pada lebar $t_{1}$. Dengan metode ini, nilai $t_{3}$ dan $T$ dapat diatur dan diprogram secara independen sehingga dapat memudahkan pengguna dalam pengaturan kedua parameter pulsa tersebut. 
Pembangkitan Pulsa Orde Nanodetik Berbasis Mikrokontroler Untuk Eksitasi Transduser Ultrasonik

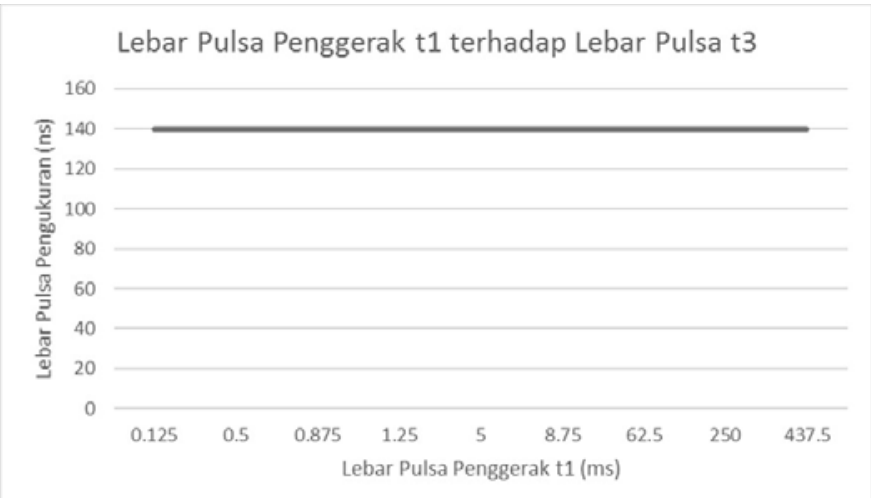

Gambar 9. Pembentukan Lebar Pulsa $T_{3}$ Orde Nanodetik dari Variasi Lebar Pulsa $t_{1}$

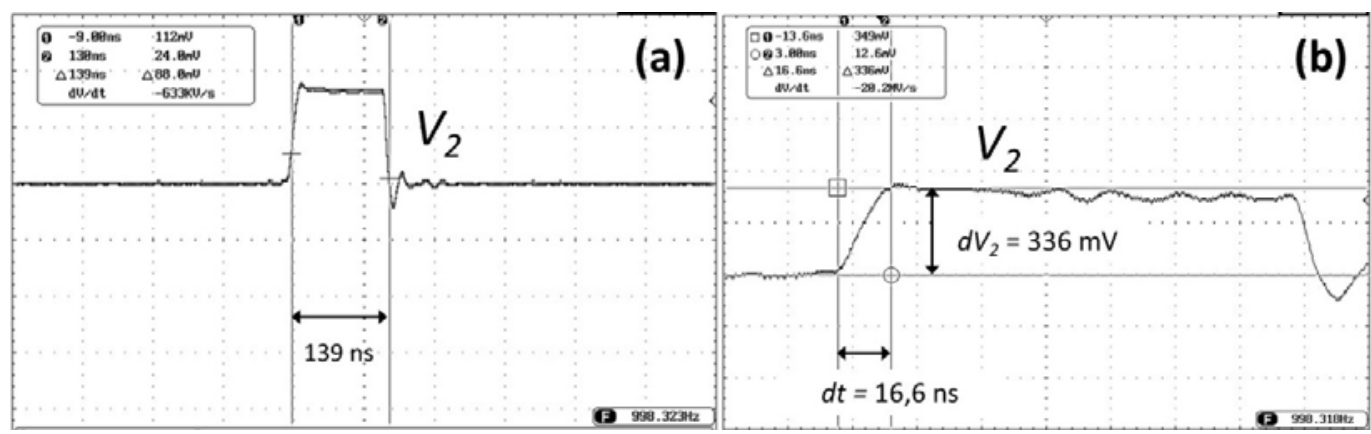

Gambar 10. Pengujian pulsa $V_{2}$ orde nanodetik (a) lebar 139 ns dan (b) laju perubahantegangan (slew rate) sinyal $V_{2}$

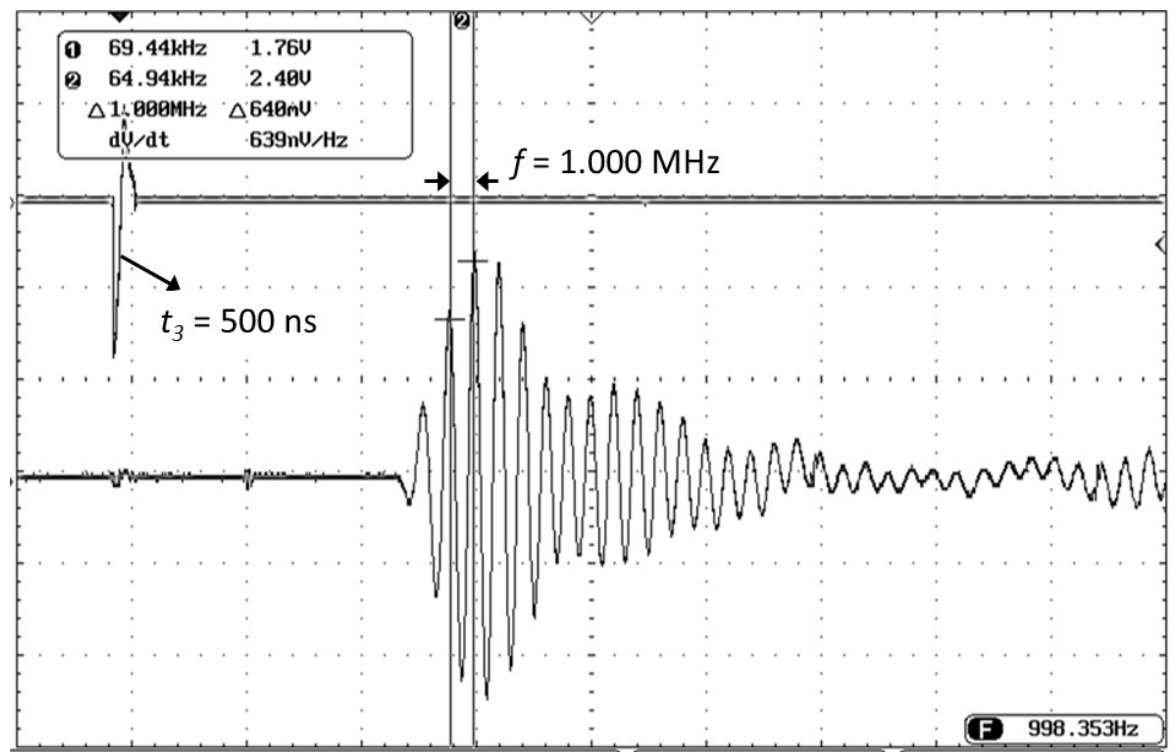

Gambar 11. Sinyal Ultrasonik di Transduser Penerima Rx setelah Merambat melalui Medium Air 
Karakteristik pulsa eksitasi $V_{3}$ ditentukan dari pulsa $V_{2}$. Salah satu karakteristik penting dalam pembentukan pulsa lebar orde nanodetik adalah parameter laju perubahan-tegangan (slew rate, $S R$ ) pulsa yang dihitung dengan Persamaan (2). Dengan pengaturan maksimum, lebar pulsa sinyal $V_{2}$ diperoleh 139 ns seperti tampilan Gambar 10.a pada skala waktu 100 ns/div. Untuk pengukuran nilai SR, tampilan osiloskop sinyal $V_{2}$ diperbesar pada skala waktu 20 $\mathrm{ns} /$ div. Dengan perubahan tegangan dan waktu pada tepi positif $V_{2}$ masing-masing adalah $336 \mathrm{mV}$ dan $16,6 \mathrm{~ns}$ maka nilai SR pulsa $V_{2}$ adalah $336 \mathrm{mV} / 16,6 \mathrm{~ns}$ yaitu $0,02024 \mathrm{~V} / \mathrm{ns}$. Setelah melalui penyaklaran MOSFET nilai tegangan $d V_{3}$ menjadi $50 \mathrm{~V}$ sehingga nilai SR pulsa $V_{3}$ adalah $3,01 \mathrm{~V} / \mathrm{ns}$. Nilai standar SR generator pulsa untuk eksitasi transduser ultrasonik adalah sekitar $3 \mathrm{~V} / \mathrm{ns}$ (Hsia, Hsiao, \& Huang, 2019). Hasil ini menunjukkan bahwa pulsa generator yang dibangun memenuhi kriteria untuk keperluan eksitasi transduser.

$$
\mathrm{SR}=\frac{d V}{d t}
$$

Dengan nilai $d V$ adalah perubahan tegangan $(\mathrm{V})$ dan $d t$ adalah perubahan waktu (s).

Gambar 11 memperlihatkan silnyal gelombang ultrasonik yang diterima oleh transduser Rx. Sinyal ini adalah satu paket gelombang ultrasonik yang dihasilkan dari satu eksitasi pulsa $V_{3}$. Berdasarkan pengukuran, frekuensi sinyal terima adalah sekitar $1,00 \mathrm{MHz}$. Nilai ini sesuai dengan rentang frekuensi kerja transduser dengan toleransi $\pm 0,05 \%$ atau $\pm 50 \mathrm{kHz}$. Sinyal terima berbentuk sinusoidal teredam sesuai karakteristik transduser. Hasil ini menunjukkan bahwa gelombang ultrasonik telah dibangkitkan dari transduser Tx, merambat melalui medium dan diterima di transduser $\mathrm{Rx}$, sehingga membuktikan bahwa pulsa $V_{3}$ telah mengeksitasi transduser ultrasonik sesuai frekuensi kerjanya melalui pengaturan lebar pulsa eksitasi.

\section{KESIMPULAN}

Generator pembangkit pulsa terprogram berbasis mikrokontroler Arduino Uno (ATMega328P) telah dibuat dan diuji. Hasil pengujian menunjukkan bahwa sistem dapat membangkitan pulsa repetitif dengan lebar pulsa hingga orde 140 ns. Pengaturan lebar pulsa dan interval pulsa dapat dilakukan secara terprogram melalui tombol-tombol tekan (PB). Seluruh parameter pulsa tersebut dapat ditampilkan pada peraga LCD. Berdasarkan hasil pengujian, dapat disimpulkan bahwa sistem berfungsi sesuai rancangan, sistem dapat membangkitkan pulsa repetitif dengan lebar pulsa hingga 140 ns dengan parameter interval dan lebar yang dapat diprogram.

\section{UCAPAN TERIMA KASIH}

Penelitian ini didukung oleh Kemenristekdikti melalui skim Riset Dasar (RD) Universitas Padjadjaran tahun anggaran 2019. Kami mengucapkan terima kasih kepada Kemenristekdikti atas pendanaan RD Universitas Padjadjaran No. 2831/UN6.D/LT2019 Tahun Anggaran 2019.

\section{DAFTAR RUJUKAN}

Aydn, E. A., \& Güler, I. (2010). Design of PIC-Controlled pulsed ultrasonic transmitter for measuring gingiva thickness. Instrumentation Science and Technology, 38(6), 411-420. https://doi.org/10.1080/10739149.2010.509149 
Pembangkitan Pulsa Orde Nanodetik Berbasis Mikrokontroler Untuk Eksitasi Transduser Ultrasonik

Chaney, A., \& Sundararajan, R. (2004). Simple MOSFET-based high-voltage nanosecond pulse circuit. IEEE Transactions on Plasma Science, 32(5), 1919-1924. https://doi.org/10.1109/TPS.2004.835966

Ega, M., Suhendi Syafei, N., Mukti Wibawa, B., \& Hidayat, D. (2016). Proseding Seminar Nasional Fisika dan Aplikasinya Sabtu.

Hidayat, D., Syafei, N. S., Wibawa, B. M., \& Tumbelaka, B. Y. (2018). Fourier transform of high frequency ultrasonic waves propagated with a transmission mode. Journal of Physics: Conference Series, 1080(1). https://doi.org/10.1088/1742-6596/1080/1/012034

Hidayat, Darmawan, Ismail, T., Syafei, N. S., \& Wibawa, B. M. (2018). Generator Pulsa Spike Terprogram untuk Pemicu Transduser Ultrasonik. JTERA (Jurnal Teknologi Rekayasa), 3(2), 295-302. https://doi.org/10.31544/jtera.v3.i2.2018.295-302

Hidayat, Darmawan, Setianto, S., Syafei, N. S., \& Wibawa, B. M. (2018). MOSFET-based high voltage short pulse generator for ultrasonic transducer excitation. AIP Conference Proceedings, 1927. https://doi.org/10.1063/1.5021211

Hidayat, Darmawan, Syafei, N. S., Wibawa, B. M., \& Tumbelaka, B. Y. (2018). Fabrikasi Transformator Step-up 1-kV Fasa Tunggal untuk Generator Pemicu Transduser Ultrasonik. Jurnal Teknologi Rekayasa, 3(1), $11 \quad$ - 16. https://doi.org/10.31544/jtera.v3.i1.2018.11-16

Hsia, C., Hsiao, Y. C., \& Huang, Y. C. (2019). A single-chip high-voltage integrated actuator for biomedical ultrasound scanners. Sensors (Switzerland), 19(23). https://doi.org/10.3390/s19235063

Ingale, K. V, \& Kale, Y. B. (2017). ULTRASONIC HIGH VOLTAGE PULSER. In International Journal of Industrial Electronics and Electrical Engineering.

Jaffar, D. S. abdul, K, M., \& Y.B, G. (2016). Design of High Voltage Pulse Generator and Receiver Circuit for Ultrasonic velocity and Absorption Measurements In liquids. Ijireeice, 4(1), 88-90. https://doi.org/10.17148/ijireeice.2016.4121.

Svilainis, L., Chaziachmetovas, A., \& Dumbrava, V. (2015). Half bridge topology 500 v pulser for ultrasonic transducer excitation. Ultrasonics, 59, 79-85. https://doi.org/10.1016/j.ultras.2015.01.014

Vyaghra, R. V, Sharma, S. J., \& Rajagopalan, S. (2016). Design of Microcontroller Based MultiFrequency Ultrasonic Pulser Receiver. In Journal of Engineering Research and Applications, 6.

Wu, J.-X., Chen, P.-J., Wang, C.-L., Chen, G.-C., \& Chen, T. (n.d.). Development of a Bipolar Pulse Generator for High-Frequency Ultrasound Imaging Systems. 